\title{
Association between Student Achievement and Engagement in Computer-Enhanced Instruction in Mathematics
}

\author{
Jarrent R. Tayag1,", Marycris B. Lenon ${ }^{2}$, Angelie M. Sotto², Joseph R. Bacanay ${ }^{2}$ \\ ${ }^{1}$ College of Education, Angeles University Foundation, Philippines \\ ${ }^{2}$ Integrated School, Angeles University Foundation, Philippines
}

Received December 23, 2019; Revised January 27, 2020; Accepted February 18, 2020

Copyright $\mathrm{C} 2020$ by authors, all rights reserved. Authors agree that this article remains permanently open access under the terms of the Creative Commons Attribution License 4.0 International License

\begin{abstract}
Learning analytics has provided significant insights on how students learn in a computer-enhanced environment. The present study investigated the association between the math achievement of 43 th grade pupils and their extent of engagement to a math computer program. Achievement test scores were correlated with learning analytics data from the program. Results revealed that pupils spend an average of 539 minutes in the computer with 460 minutes spent engaging with the program. An average of 26 minutes was recorded as wasted time. For an entire year, an average of 43 topics were mastered, 3182 problems were attempted to be answered, and 460 worksheets were successfully completed by the pupils. Further, it was found out that the engagement time of the pupils either to the computer $(r=0.289)$ or to the program $(r=0.259)$ did not significantly associate with their math achievement. Rather, the number of topics mastered $(\mathrm{r}=0.420)$, total points earned $(\mathrm{r}=0.386)$, number of problems attempted $(\mathrm{r}=0.317)$, and worksheets completed $(\mathrm{r}=0.305)$ proved to have significant relationship with the math achievement of the pupils. The results enrich previous studies highlighting the association between student engagement and achievement in computer-enhanced environments. Results emphasize that it is not the mere engagement time that may impact student achievement, but rather, the quality of activities that they engage into.
\end{abstract}

Keywords Math Achievement, Computer-Enhanced Instruction, Student Engagement

\section{Introduction}

Technology has become an integral part of the teaching and learning process in many schools. Countries are investing significant amount of resources to upgrade the technologies and facilities available to the educational system to ensure that teachers and students have access to these materials. Using technology, learning has become more flexible with learning hours not only confined within the predetermined time of the students in the classroom. Through online learning, teachers can provide learning experiences to students even when the latter could not afford to come to the school grounds. Despite the absence of the teacher, the performance of the student is monitored and evaluated, thus, ensuring that learning is indeed taking place.

While online learning is available for students, most schools would still hold the conventional face to face classroom sessions. Classroom activities such as lectures and discussions, group activities, brainstorming, and the like are still designed, implemented, and assessed by teachers. Nevertheless, even these kinds of activities have also been enhanced by technology. The use of interactive whiteboards, projectors, augmented and virtual reality, and other similar equipment has indeed changed the way teachers deliver their instruction. Further, the wide use of the internet and other mobile technologies has also provided easy and more comprehensive resources for students to complete their academic tasks. Schmid and Petko (2019) noted that technology has afforded personalized learning among students [1]. With the students gaining control of the pace by which they learn topics in school, they become more accountable for their own learning. A learning environment conducive of effective technology use, through relevant teaching strategies, is, however, a crucial aspect in developing positive attitude towards this type of learning among students. Among the persisting forms of technologyenhanced interaction between teachers and students at present are computer programs that deliver the instruction 
and complement the classroom experience of students. It has a point of interest whether these computer-enhanced instructions can be of significant impact in the learning achievement of students. The present study aimed to investigate the relationship between the achievement scores and engagement of learners towards computerenhanced instruction in elementary mathematics.

\section{Literature Review}

Technology tend to have different effects towards different types of students. In a study conducted by Reinhold and his associates (2019), they found out that high-achieving students do not benefit so much in technology in terms of their academic achievement [2]. However, they did note that technology can have significant impact on the achievement of low-achieving students. Rutten, van Joolinger, and van der Veen (2012) also concluded through a review study that computer simulations used in science education have enhanced the delivery of instruction among teachers [3]. Ruchter, Klar, and Geiger (2010) asserted that technology does not only improve student achievement, but also enhances student engagement [4].

Seo and Woo (2010) reported the design and use of computer-assisted instruction in teaching mathematics for students with learning disabilities in the early elementary grades [10]. Another study conducted to elementary and middle school students revealed a significant rise in the math achievement of underachieving students [11]. Volk, Cotic, Zajc, \& Stacic (2017) reported that students who are exposed to tablet-based math curriculum tend to have better outputs than their counterparts [12]. While the reported effect sizes may be small, these findings still corroborate with the other studies that lean towards the positive influence of technology in the teaching of mathematics. In fact, studies such as that of Jagust, Boticki, and So (2018) state that infusing relevant strategies and techniques such as gamification through tablets can increase student performance in math [13].

While the aforementioned studies are in support to the positive impact of using computer-enhanced instructions in teaching, $\operatorname{Ke}$ (2008) noted that it is essential to situate the learning activities and effectively embed them within the computer program. Otherwise, the students may be engaged, but would not have significant gains in terms of their cognitive test performance and metacognition [14].

These studies among others point to the potent impact of technology to the various aspects of teaching and learning. Because of these strides, it is not surprising that schools are aggressively moving towards the development and implementation of different technology-enhanced systems to aid the instruction of teachers. Schools are investing towards the development of computer programs and training of teachers in the integration of these programs into the teaching process.

\section{Materials and Methods}

\subsection{Research Design}

The study employed a correlational design in which various elements in the learning analytics of a commercial math software, have been associated with the achievement scores of the students. The students were exposed to the use of the computer software for a year. The math software was introduced to the students at the beginning of the year and each student was given their individual accounts. The software is accessible through the internet, so students are encouraged to utilize it in practicing their math skills even at home. In school, students were attending their regular face-to-face classes with their math teachers. Once a week, for one hour, the teacher assists the students to the computer laboratory to facilitate quizzes and drills using the software. The teacher is also able to design her own worksheets using the software. This allows her to create relevant follow ups to the lessons discussed in the class. The use of the software was supposed to support home practice of the students with the math skills taught in class. The teacher can monitor the performance of the students whenever they accomplish worksheets. Students are also free to choose which lesson worksheet they would like to practice. Because of such arrangement, the teacher does not account much of the worksheets against the grades of the students. Supervised quizzes and exercises still form significant parcels of the grades of the students at the end of the year. The data were gathered through the learning analytics of the software after a year of usage by the students. These data have been exported and analyzed using SPSS.

\subsection{Data Sources}

\subsubsection{Math Software Learning Analytics}

The math software is used to supplement the classroom face-to-face interaction of the students. It allows the students to access worksheets about different math topics covered in class. Teachers can also customize worksheets that students can take at home. For most of the time, students use their accounts to practice or take advance lessons. Similar with other software, its learning analytics that allows the teachers to monitor the activities of their students. For this study, the following elements have been accounted for: engagement time with computer, engagement time with program, number of topics mastered, points earned, number of problems attempted to be answered, number of worksheets completed, and wasted time.

\subsubsection{Achievement Test Scores}

An achievement test in math was administered at the end of the academic year by another commercial company. The achievement test includes items from the different topics 
covered during the academic year. The participants had a mean score of 59.40 in the achievement test.

\subsection{Participants}

The participants in the study were 43 4th grade students from a private school in the Philippines. They have been using the software since the 1st grade and are well acquainted with its features. All of them are utilizing the software either at home or in school.

\section{Results and Discussion}

Table 1 presents the mean data for each of the elements in the learning analytics of the software. The difference between the engagement time with computer and the program indicates that there are instances wherein the student logs into the software yet remains idle, i.e., the student is not accessing any of the contents. Considering that the data have been gathered at the end of the year, the average time spent in the program is not quite impressive. This may be attributed to the practice of using the software as a supplementary material rather than a compulsory source of activities for the students. Within the classroom, the teacher proceeds with the intended lessons and trusts that students who may be having difficulty will utilize the software for practice and drills. Unfortunately, there were a few students who had very minimal interaction to the program even after a year, thereby pulling the average engagement. Howard, Ma, and Yang (2016) actually reported the same weak engagement among students in terms of the use of digital technologies [5]. However, they noted that such engagement is espoused by a positive attitude that the students can execute computer-related tasks without the supervision of their teachers. In the light of the present study, the authors agree that the apparent minimal engagement of the students may be because of the strong reliance to the face-to-face interaction of the students and teachers rather than in the independent use of the software. While students may be actively encouraged to use the software to practice, they are still drawn towards doing the activities in the classroom with the supervision of their teachers.

Table 1. Engagement quality of learners to computer software

\begin{tabular}{|l|c|}
\hline Learning Analytics Elements & Mean \\
\hline Engagement time with computer (in mins) & 539 \\
\hline Engagement time with program (in mins) & 460 \\
\hline Number of topics mastered & 43 \\
\hline Points earned & 24501 \\
\hline Number of problems attempted to be answered & 3182 \\
\hline Number of worksheets completed & 460 \\
\hline Wasted time & 26 \\
\hline
\end{tabular}

To further understand the data, the learning analytics elements were correlated with the achievement test scores of the students. As seen from Table 2, neither the engagement to the computer nor to the program prove to be significantly associated with the achievement test scores of the students. This essentially suggests that increased use of the software does not equate to better student achievement. This confirms the findings of Castaño - Muñoz, Duart, and Sancho - Vinuesa (2014), which stated that students who spend more time in computer-enhanced instructions manifest better achievement [6]. Given that math is a subject highly dependent on practice and drills, students may find computer software helpful in providing numerous exercises for the topics that they learned in class. However, for students who may be struggling to learn the rudiment of the topic and are planning to use the software, the activity may not prove to be very efficient as it leaves them baffled as to why their answers were incorrect. Succeeding trials may simply lead to frustration as they cannot move forward through the series of worksheets. What appears to be the challenge is the absence of an expert who can clearly diagnose the difficulty of the student and guide them in accomplishing the worksheets. Abachi and Muhammad (2014) and Macaranas, Tulabut, and Tayag (2019) supported this by asserting that it is not the length of time spent by students in computer software that may cause change in their academic achievement, but rather the quality of instruction that they receive [7] [8].

Table 2. Association of engagement indicators to achievement scores

\begin{tabular}{|c|c|}
\hline Indicators & $\begin{array}{c}\text { Correlation } \\
\text { Coefficient }\end{array}$ \\
\hline Engagement time with computer (in mins) & 0.289 \\
\hline Engagement time with program (in mins) & 0.259 \\
\hline Number of topics mastered & $0.420^{* *}$ \\
\hline Points earned & $0.386^{*}$ \\
\hline Number of problems attempted to be \\
answered & $0.317^{*}$ \\
\hline Number of worksheets completed & $0.305^{*}$ \\
\hline Wasted time & -0.014 \\
\hline
\end{tabular}

**Correlation significant at 0.01 level

*Correlation significant at 0.05 level

While there is no significant relationship between the engagement time and achievement of students, significant associations were noted with the number of topics mastered, points earned, number of problems attempted to be answered, and number of worksheets completed. Banking on the previous contentions that the software is a supplement to the classroom instruction of the teacher, it is not surprising to establish these associations. The above data can be viewed as a confirmation of the ability of the software to indeed supplement teacher instruction by providing the students with additional learning time. What may be amplified from the results is the significant association between the number of attempts of the student 
and their achievement. While students may be encountering challenges in the completion of some worksheets, their active attempts may be helping them learn the concepts. The mechanism by which this action happens may not be empirically proven by the present study. However, the authors propose that even if students may be challenged by the difficult worksheets in the software, they are able to realize these difficulties and can focus more on these concepts when they meet their teachers in the classroom. This may be an evidence of metacognitive strategies used by students to determine challenged areas in their learning process.

It is important to note that the positioning of computerenhanced activities in the curriculum affected the results of the study. The program is not regularly used as part of the classroom activities; thus, students are simply advised to utilize it to practice skills that they have learned in the classroom. Other similar studies such as that of Zainuddin and others (2019) integrated the technology in the face-toface classroom interaction of the teachers [9]. This makes the participation of the students compulsory since they can be easily monitored by the teacher during the classroom session. In such setup, engagement time may not be a valid indicator of the impact of technology. The present study relies on the intrinsic motivation of the students to engage into the program outside the classroom. Compared to existing studies in the field, the results of this study are deemed to be reflective of the actual behavior of students towards these types of technology.

It is, however, necessary to consider the various features and interfaces that similar programs have in understanding how they entice students to engage into them. The participants of the present study are elementary students, who are typically attracted to interactive materials. Given that the program provides immediate feedback and extrinsic reinforcement in the form of badges and stars, it is justified to expect that students would have more engagement time for the program. The authors are hypothesizing the role of the curricular load that students have in their capacity to engage into the program. In the Philippines, $4^{\text {th }}$ graders usually stay in school for six to seven hours, taking up to 10 different subjects every day. Because the computer-enhanced activities are not done as part of the class hours, students feel the need to use extended hours after their school to access the program. In some cases, the students even have to complete a few class assignments before they can engage into the software. A few students also have to attend tutorial classes after their class. Because of the heavy academic load of the students, it is possible that engaging with the program may be at the latter part of the list of the students for the day. In an attempt to ensure that students are engaging with the program, the teachers may assign worksheets that need to be completed by the students as part of their coursework. This compels students to complete the worksheets because they become part of their course marks. However, even in this setup, there are still a few students who fail to accomplish the worksheets.

The analysis that the authors used in this paper focused on the curricular aspect of integrating computer-enhanced instruction. In reality, however, the lack of access to internet and computers may still be contributory to the concerns at hand.

\section{Conclusions}

The present study aimed to investigate the relationship between student achievement and engagement to computer-enhanced instruction. It has been found out that the students have very minimal engagement with the program. It is likewise seen that engagement time has no significant association with the math achievement of the students. The number of topics mastered and completed worksheets, however, are significantly related to the math achievement. Several considerations that may affect the engagement of students to computer-enhanced instruction are the curricular design and academic load. The results of this study lead towards a call for further research on how to appropriately implement computer-enhanced instruction. Hinted by the results of the study is the need to reevaluate computer programs used in instruction. These computer programs must not only pass the technical standards but also be pedagogically sound to entice students to utilize them. Math, in particular, is a subject that requires constant practice to master the target skills. If students will be engaged into the use of the software, they are likely to have a number of opportunities to learn the skill. However, teachers must also be mindful of the pedagogical designs used in these programs. As seen in the results, engagement does not equate to learning; thus, it is a challenge for teachers to carefully integrate their lessons into the program.

Because the use of these computer programs is not limited to the school campus, further studies can investigate how parents support the learning of their children amidst the presence of these materials. Tutors may also be guided in the conduct of review sessions for young learners. A qualitative study on the experiences of the students in the use of these programs can also be conducted to document the possible challenges in the use of the program in school and at home.

\section{REFERENCES}

[1] Schmid, R. \& Petko, D. (2019). Does the use of educational technology in personalized learning environments correlate with self-reported digital skills and beliefs of secondary students? Computers \& Education, 136, 75-86.

[2] Reinhold, F., Hoch, S., Werner, B., Richter-Gebert, J., \& Reiss, K. (2019). Learning fractions with and without 
educational technology: What matters for high-achieving and low-achieving students? Learning and Instruction, 65

[3] Rutten, N., van Joolingen, W.R., \& van der Veen, J.T. (2012). The learning effects of computer simulations in science education. Computers \& Education, 58 (1), 136-153.

[4] Ruchter, M., Klar, B., \& Geiger, W. (2010). Comparing the effects of mobile computers and traditional approaches in environmental education. Computer \& Education, 54, (4), 1054-1067.

[5] Howard, S.K., Ma, J., \& Yang, J. (2016). Student rules: Exploring patterns of students' computer-efficacy and engagement with digital technologies in learning. Computers \& Education, 101, 29-42.

[6] Castaño - Muñoz, J., Duart, J. M., \& Sancho - Vinuesa, T. (2014). The Internet in face - to - face higher education: Can interactive learning improve academic achievement? British Journal of Educational Technology, 45(1), 149-159.

[7] Abachi, H. R., \& Muhammad, G. (2014). The impact of mlearning technology on students and educators. Computers in human behavior, 30, 491-496.

[8] Macaranas, D.J.D., Tulabut, R.J., \& Tayag, J.R. (2019). Relation between LMS learning behaviors and academic achievement of undergraduate students.

[9] Zainuddin, Z., Shujahat, M., Haruna, H., \& Chu, S.K.W. (2019). The role of gamified e-quizzes on student learning and engagement: An interactive gamification solution for a formative assessment system. Computers \& Education, 145.

[10] Seo, Y. J., \& Woo, H. (2010). The identification, implementation, and evaluation of critical user interface design features of computer-assisted instruction programs in mathematics for students with learning disabilities. Computers \& Education, 55(1), 363-377.

[11] Suppes, P., Liang, T., Macken, E. E., \& Flickinger, D. P. (2014). Positive technological and negative pre-test-score effects in a four-year assessment of low socioeconomic status K-8 student learning in computer-based Math and Language Arts courses. Computers \& Education, 71, 23-32.

[12] Volk, M., Cotič, M., Zajc, M., \& Starcic, A. I. (2017). Tabletbased cross-curricular maths vs. traditional maths classroom practice for higher-order learning outcomes. Computers \& Education, 114, 1-23.

[13] Jagušt, T., Botički, I., \& So, H. J. (2018). Examining competitive, collaborative and adaptive gamification in young learners' math learning. Computers \& education, 125, 444-457.

[14] Ke, F. (2008). A case study of computer gaming for math: Engaged learning from gameplay?. Computers \& education, 51(4), 1609-1620. 